\title{
Promoción de crecimiento en trigo (Triticum turgidum L. subsp. durum) por la co-inoculación de cepas nativas de Bacillus aisladas del Valle del Yaqui, México \\ Growth promotion on wheat (Triticum turgidum L. subsp. durum) by co- inoculation of native Bacillus strains isolated from the Yaqui Valley, Mexico
}

Jonathan Rojas Padilla ${ }^{1}$, Luis Abraham Chaparro Encinas ${ }^{1}$, Rosa Icela Robles Montoya ${ }^{1}$, Sergio de los Santos Villalobos ${ }^{1}$

Palabras clave: RPCV; producción sostenible; consorcio bacteriano; inoculante microbiano Keywords: PGPR; sustainable production; bacterial consortium; microbial inoculant

\section{Resumen}

Introducción: Las rizobacterias promotoras del crecimiento vegetal (RPCV) son un grupo de bacterias rizosféricas con la habilidad de promover el crecimiento y la salud de las plantas, y restaurar la fertilidad del suelo. El presente estudio tuvo como objetivo evaluar la promoción del crecimiento en el cultivo de trigo (Triticum turgidum L. subsp. durum) por la co-inoculación de cepas nativas del género Bacillus aisladas del Valle del Yaqui, México, para su potencial uso como inoculante microbiano.

Método: Tres cepas bacterias obtenidas de la Colección de Microorganismos Edáficos y Endófitos Nativos (COLMENA), aisladas del cultivo de trigo en el Valle del Yaqui, fueron estudiadas. Primeramente, se realizó la identificación molecular de las cepas mediante la secuenciación del gen 16S RNAr, mediante la plataforma Sanger. Además, las cepas bacterianas fueron caracterizadas metabólicamente mediante actividades funcionales asociadas a la promoción del crecimiento vegetal (producción de indoles, solubilización de fósforo insoluble, y producción de sideróforos). Finalmente, el impacto de la inoculación de estas cepas individualmente, y en consorcios fue determinado utilizando el cultivo de trigo (Triticum turgidum L subsp. durum) como planta modelo, simulando las condiciones edafo-climáticas del Valle del Yaqui. Las variables morfométricas medidas fueron la longitud aérea y de raíz, peso seco aéreo y de raíz, e índice de biovolumen.

Resultados: Las cepas TRQ8, TRQ65 y TE3 ${ }^{\mathrm{T}}$ fueron afiliadas taxonómicamente a Bacillus megaterium, Bacillus paralicheniformis y Bacillus cabrialesii, respectivamente; dicha clasificación fue soportada por sus características macro-microscópica como: su forma bacilar y tinción Gram positiva, que son características propias de este género bacteriano. Las cepas en

\footnotetext{
${ }^{1}$ Instituto Tecnológico de Sonora, Laboratorio de Biotecnología del Recurso Microbiano. E-mail: sergio.delossantos@itson.edu.mx

(C) Universidad De La Salle Bajío (México)
} 
Promoción de crecimiento en trigo (Triticum turgidum L. subsp. durum) por la co-inoculación de cepas nativas de Bacillus aisladas del Valle del Yaqui, México

estudio tuvieron la capacidad de producir indoles, siendo B. paralicheniformis TRQ65 quien presentó mayor producción con $39.29 \mu \mathrm{g} / \mathrm{mL}$. Mientras que en la prueba de solubilización de fósforo insoluble las 3 cepas mostraron la capacidad en un rango de índice de solubilización de 1.37 a 1.43; finalmente, solamente la cepa B. megaterium TRQ8 mostró un índice de producción de sideróforos de 8.17. La inoculación del consorcio $B$. megaterium TRQ8 $+B$. paralicheniformis TRQ65 mostró los mayores incrementos en las 5 variables medidas en la planta, diferencia significativa $(\mathrm{p}<0.05)$ vs. el tratamiento no inoculado, la longitud aérea y radical mostró un incremento de 6 y 10\% respectivamente, mientras que la biomasa seca aérea aumentó $60 \%$ y la biomasa seca radicular se incrementó en $82 \%$. El índice de biovolumen se incrementó en $18 \%$ por la inoculación de dicho consorcio bacteriano.

Discusión o Conclusión: Las cepas estudiadas presentan características de promoción de crecimiento in vitro e in vivo. Sin embargo, la co-inoculación de B. megaterium TRQ8 y $B$. paralicheniformis TRQ65 incrementó su capacidad de promoción del crecimiento en plantas de trigo. Por lo cual, los mecanismos asociados a dicho efecto, así como sus funciones ecológicas e interacción con los factores bióticos y abióticos de los agro-sistemas deben ser estudiadas para su validación en diferentes agroecosistemas, antes de su utilización extensiva como un inoculante microbiano.

\begin{abstract}
Introduction: The rising demand for food worldwide required the development of sustainable production alternatives. Plant growth-promoting rhizobacteria (PGPR) is a group of rhizospheric bacteria with the ability to promote good plant health and growth, as well as to restore soil fertility. The objective of this study was to evaluate the growth promotion of wheat (Triticum turgidum L. subsp. durum) plants, by co-inoculation of native Bacillus strains isolated from the Yaqui Valley, Mexico, for their potential use as a microbial inoculant.

Methods: Three bacterial strains obtained from the Collection of Edaphic Microorganisms and Native Endophytes (COLMENA), isolated from wheat commercial fields in the Yaqui Valley, were studied. First, the molecular identification of strains was performed by sequencing the $16 \mathrm{~S}$ rRNA gene, by using the Sanger platform. In addition, bacterial strains were metabolically characterized by functional activities associated with the promotion of plant growth (production of indoles, solubilization of insoluble phosphorus, and production of siderophores). Finally, the
\end{abstract}


impact of the inoculation of these individual strains, and in consortia was determined in durum wheat (Triticum turgidum L subsp. durum), simulating the edaphoclimatic conditions of the Yaqui Valley. The morphometric variables measured were aerial and root length, aerial and root dry weight, and biovolume index.

Results: The strains TRQ8, TRQ65, and TE $3^{\mathrm{T}}$ were taxonomically affiliated with $B$. megaterium, B. paralicheniformis, and B. cabrialesii, respectively. This classification was supported by its macro-microscopic characteristics such as its bacillary form and Gram-positive staining, which are characteristic of this bacterial genus. Those strains had the ability to produce indoles, strain $B$. paralicheniformis TRQ65 had the highest production with $39.29 \mu \mathrm{g} / \mathrm{mL}$. All studied strains showed the ability to solubilize insoluble phosphorus, solubilization index ranged from 1.37 to 1.43. Finally, only B. megaterium TRQ8 showed a siderophore production index of 8.17. Inoculation of the B. megaterium TRQ8 + B. paralicheniformis TRQ65 consortium showed the greatest increases in the 5 variables measured, significant difference $(\mathrm{p}<0.05)$ vs. the uninoculated treatment, aerial and radical length showed an increase of 6 and $10 \%$, respectively, while aerial dry biomass increased $60 \%$, and root dry weight increase $82 \%$. This consortium showed an $18 \%$ higher biovolume index than the un-inoculated treatment.

Discussion or Conclusion: The strains studied showed growth promotion traits in vitro and in vivo. However, co-inoculation of these strains increased their ability to promote growth in wheat plants. Therefore, the mechanisms associated with this effect, as well as their ecological functions and interaction with the biotic and abiotic factors of agro-systems must be further studied for extensive use as a microbial inoculant.

\section{Introducción}

La creciente demanda de alimentos a nivel mundial representa un desafío para los próximos 30 años, ya que el crecimiento acelerado de la población para el año 2050 ( $>9 \times 10^{9}$ habitantes) demandará duplicar la producción de alimentos (Godfray H.C.J. et al., 2010, p. 812). Entre los alimentos más importantes se encuentran los cereales, cuya producción deberá incrementarse a $1 \times 10^{6}$ millones de toneladas anuales, para 2050 (United Nations, 2015, p. 66). Entre estos, el trigo es uno de los alimentos de mayor interés, debido a su aporte calórico y proteico, así como una fuente importante de micronutrientes (Poudel \& Bhatta, 2017, p. 3). 
La importancia de este cereal ha conducido a investigaciones exitosas en el Valle del Yaqui, Sonora, México, enfocadas a incrementar su productividad, desde los inicios de la Revolución Verde promovida por el Dr. Norman E. Borlaug (1968, p. 10). La gran demanda global por este cereal ha generado opciones productivas cada vez más robustas y eficientes, incluyendo la generación de variedades con mayores rendimientos, más calidad del grano y resistentes a enfermedades; así como la aplicación de nuevas prácticas de manejo agrícola, incluyendo técnicas y densidades de siembra, métodos de labranza, calendarios de riego, control fitosanitario y fertilización, entre otras tecnologías (Matson \& Jewett, 2013, p. 299).

Sin embargo, el impacto de las prácticas agrícolas en combinación con las condiciones climáticas prevalecientes en el Valle del Yaqui (temperaturas extremas, baja precipitación pluvial, y alta evapo-transpiración), puede ser causa de los suelos salinos con bajo contenido de materia orgánica y nutrientes observados en la región (Cortes-Jimenez et al., 2009, p. 135), impactando negativamente el óptimo aprovechamiento de los insumos agrícolas por el cultivo (i.e. sólo el 23\% de nitrógeno aplicado es aprovechado por el cultivo) (Grahmann et al., 2019, p. 5). De esta manera, a nivel mundial, el rendimiento del trigo ha disminuido gradualmente ( $9 \%)$ durante 1981 a 2010 (Asseng, 2015, p. 304). Por lo tanto, el mantener la productividad sustentable de trigo realizando estudios eco-fisiológicos y con microorganismos (MOOS) benéficos, son requeridos para la generación de alternativas de producción de bajo impacto bajo las condiciones edafo-climáticas actuales y futuras. Lo cual permitirá generar conocimiento científico sobre la interacción del trigo con los factores abióticos y bióticos del agro-sistema, destacando tener una mejor comprensión de las interacciones planta-suelo.

El ecosistema suelo puede contener una extensa diversidad y población de microorganismos, se estima que el $90 \%$ son bacterias, $9 \%$ actinomicetos y $1 \%$ hongos, siendo la rizósfera donde se encuentra la mayor población microbiana cultivable que se estima en $1 \times 10^{6}$ $\mathrm{UFC} / \mathrm{cm}^{3}$ (Sgroy et al., 2009, p. 371). La rizósfera es la porción de suelo donde los procesos mediados por MOOS están influenciados por el sistema radicular (Kloepper et al., 2004, p. 219). Esta zona incluye el suelo que está en contacto con las raíces de las plantas, y a menudo se extiende a pocos milímetros fuera de la superficie de las mismas (Bringhurst, Cardon, \& Gage, 2001 , p. 8), teniendo un importante ambiente de interacción entre planta y microorganismos (Gray \& Smith, 2005, p. 395). En esta zona la planta excreta una amplia diversidad de compuestos como aminoácidos y azúcares, los cuales proveen una fuente rica de energía y 
nutrientes para los MOOS involucrados en las interacciones que pueden ser benéficas, neutras o perjudiciales para la planta (de Souza et al., 2015a, p. 187; Scagliola et al., 2016, p. 401).

Las RPCV son un grupo de bacterias rizosféricas con la habilidad de promover el crecimiento, la salud de las plantas y restaurar la fertilidad del suelo (Valenzuela-Aragon et al., 2018). Para ello utilizan diversos mecanismos, entre los que destacan: I) la fijación biológica del nitrógeno atmosférico (Guzmán et al., 2012, p. 182; Robertson \& Groffman, 2015, p. 424); II) solubilización de minerales como fósforo (P) (Corrales et al., 2014, p. 67; Kumar et al., 2013, p. 1361); III) producción de sideróforos (Patel et al., 2018, p. 81); y IV) la habilidad de producir fitohormonas (de Souza, Ambrosini, \& Passaglia, 2015b, p. 401; Sheirdil et al., 2019, p. 12). Además de forma indirecta, las RPCV pueden actuar como agentes de biocontrol contra fitopatógenos por medio de I) la producción de sideróforos (Villarreal-Delgado et al., 2018, p. 95); II) de quitinasas (Thilagar et al., 2018, p. 813); III) de antibióticos (Cattelan et al., 1999, p. 1670; Nyambura-Ngamau, 2012, p. 6414); y IV) la competencia por espacio y nutrientes (Martínez-Viveros et al., 2010, p. 293).

De acuerdo a Numan et al. (2018, p. 21), los MOOS más reportados como RPCV habitan en la rizósfera y pertenecen a los géneros Achromobacter, Azotobacter, Azopirillum, Bacillus, Burkholderia, Enterobacter, Microbacterium, Pantoea, Pseudomonas, Rhizobium, y Streptomyces. Por ejemplo, Shaharoona et al., (2008, p. 147) reportó que la inoculación del cultivo de trigo con Pseudomonas fluorescens resultó en un incremento significativo del peso de raíz (19-43\%); número de macollos por planta (10-21\%); producción de grano (15-43\%) y rendimiento de paja (22-39\%), comparado con plantas no inoculadas. De manera similar, cepas del género Bacillus han demostrado que potencian el crecimiento de cultivos agrícolas como el tomate (Solanum lycopersicum), chile (Capsicum annuun L.), T. aestivum y T. durum (Sood et al., 2018, p. 1; Thilagar et al., 2018, p. 813; Majeed et al., 2015, p. 1; Robles-Montoya et al., 2019, p. 201).

Por otro lado, la aplicación Bacillus polimixa BcP26 resultó en un incremento significativo en la absorción de N, P y K, desde 10\% hasta $61 \%$ más que el control no inoculado, y la aplicación de B. megaterium BcM33 incrementó en $11 \%$ y $18 \%$ el peso seco de la raíz y tallo respectivamente, en el cultivo de algodón (Gossypium hirsutum) (Egamberdiyeva \& Höflich, 2004, 293). Con base en lo antes señalado, el objetivo del presente trabajo fue identificar RPCV asociadas a la rizósfera del trigo en el Valle del Yaqui, mediante I) su identificación molecular; 
Promoción de crecimiento en trigo (Triticum turgidum L. subsp. durum) por la co-inoculación de cepas nativas de Bacillus aisladas del Valle del Yaqui, México

II) características metabólicas involucradas en la promoción de crecimiento vegetal; III) el impacto de su inoculación sobre variables morfométricas en el cultivo de trigo. Esto se realizó para las tres RPCV, ya sea de forma individual y en consorcio.

\section{Método}

\section{Microorganismos y condiciones de crecimiento}

Las cepas bacterianas utilizadas (TE3 ${ }^{\mathrm{T}}$, TRQ8 y TRQ65) fueron seleccionadas con base en su capacidad de colonizar la rizósfera del cultivo de trigo, en lotes comerciales localizados en el Valle del Yaqui, Sonora, México (Valenzuela-Aragon, et al., 2018), y por su capacidad antagónica contra Bipolaris sorokiniana, el agente causal de la mancha borrosa en este cereal (Villa-Rodriguez et al., 2016, p. 2329; Villa-Rodriguez et al., 2019, p. 135). Las cepas en estudio, criopreservadas a $-80^{\circ} \mathrm{C}$ en glicerol al $10 \%$, fueron crecidas en cajas de Petri conteniendo Agar Nutritivo (AN, DIBICO ${ }^{\circledR}$ ) a $28 \pm 2^{\circ} \mathrm{C}$ por 48 h (Labnet ${ }^{\circledR} 311 \mathrm{DS}$ ). La morfología de la colonia, tamaño, color, forma y el patrón de crecimiento se registró después de las 48 horas de incubación, según lo descrito por Somasegaran y Hoben (1994). La reacción de Gram se realizó según lo descrito por Vincent y Humphrey (1970). Posteriormente, una colonia de cada cepa fue individualmente transferida a un tubo Falcon $(50 \mathrm{~mL})$ estéril $\left(121^{\circ} \mathrm{C}\right.$ y $\left.15 \mathrm{psi} / 15 \mathrm{~min}\right)$ con $20 \mathrm{~mL}$ de Caldo Nutritivo $\left(\mathrm{CN}\right.$, DIBICO $\left.^{\circledR}\right)$ y cultivadas durante $24 \mathrm{~h}$ en agitación a $120 \mathrm{rpm}$ y $28 \pm 2^{\circ} \mathrm{C}$ (Labnet $\left.{ }^{\circledR} 311 \mathrm{DS}\right)$, para los experimentos posteriores.

\section{Identificación molecular}

La identificación molecular de las cepas en estudio se realizó mediante la secuenciación del gen 16S ARNr con los oligonucleótidos $\quad$ FD1 CCGAATTCGTCGACAACAGAGTTTGATCCTGGCTCAG-3') y RD1 (5'CCCGGATCCAAGCTTAAGGAGGGGGGCCCCCC-3') (Bresler et al., 2000, p. 904). Las condiciones de la reacción en cadena de la polimerasa (PCR, por sus siglas en inglés) consistieron en una desnaturalización a $94^{\circ} \mathrm{C}$ por $3 \mathrm{~min}$, alineamiento a $55^{\circ} \mathrm{C}$ por 30 segundos, y extensión a $72^{\circ} \mathrm{C}$ por $1 \mathrm{~min}$ (lo anterior se repitió durante 35 ciclos), y una extensión final a $72^{\circ} \mathrm{C}$ (10 min). Los amplicones fueron visualizados mediante una electroforesis en gel de agarosa al $2 \%$, usando como colorante GelRedTM $\left(\right.$ BiotiumTM $^{\circledR}$ ). Los amplicones purificados fueron secuenciados mediante la plataforma Sanger. Las secuencias nucleotídicas obtenidas se editaron 
con el software FINCH TV (Geospiza, Inc.; Seattle, WA, EE. UU.; http://www.geospiza.com), y fueron comparadas con la herramienta de alineamiento local básico BLASTn de NCBI (National Center for Biotechnology Information, por sus siglas en inglés) (Altschul et al., 1990, p. 403), considerando el porcentaje de máxima identidad. Las secuencias del gen 16S ARNr fueron depositadas en la base de datos Genbank y publicadas con el número de acceso: MH057214 $\left(\right.$ TE3 $^{\mathrm{T}}$ ), MK493638 (TRQ8) y MK493706 (TRQ65).

Las secuencias anteriormente mencionadas se utilizaron para construir un árbol filogenético mediante el software CLC Sequence Viewer (CLC bio, Aarhus, Denmark), con el modelo de evolución Kimura80 (Kimura, 1980, p. 111), y el modelo de construcción NeighborJoining. Dicha construcción se realizó con base en 1000 iteraciones para el cálculo del porcentaje de bootstrap. La secuencia del gen 16S ARNr de Pseudomonas sp. (MH569548) fue utilizada como "outgroup".

\section{Caracterización in vitro de mecanismos de RPCV en las cepas de estudio}

Para la evaluación in vitro de la capacidad de promoción de crecimiento vegetal de las cepas estudiadas, el pre-inóculo fue realizado bajo las condiciones descritas anteriormente. Posteriormente se tomó $1 \mathrm{~mL}\left(1 \times 10^{6}\right.$ células $\left./ \mathrm{mL}\right)$ de cada pre-inóculo y se transfirió a $10 \mathrm{~mL}$ de $\mathrm{CN}\left(\right.$ DIBICO $\left.^{\circledR}\right)$, incubándose durante 24 horas en agitación a $120 \mathrm{rpm}$ y $28 \pm 2^{\circ} \mathrm{C}$, para después centrifugar (Labnet ${ }^{\circledR}$ Harmle Z $446 \mathrm{~K}$ ) a 3,500 rpm por $8 \mathrm{~min}$. La biomasa obtenida fue lavada por duplicado con solución salina $(0.9 \% \mathrm{NaCl})$ estéril $\left(121{ }^{\circ} \mathrm{C}\right.$ y 15 psi por $\left.15 \mathrm{~min}\right)$ y re-

suspendidos con agua destilada estéril, ajustando la concentración celular a $1 \times 10^{6}$ células $/ \mathrm{mL}$, utilizando una cámara de Neubauer para el conteo de células.

Producción de indoles. $1 \mathrm{~mL}\left(1 \times 10^{6}\right.$ células $\left./ \mathrm{mL}\right)$ de las cepas TE3 ${ }^{\mathrm{T}}$, TRQ8, y TRQ65 fueron inoculadas individualmente en $10 \mathrm{~mL}$ de CN $\left(\right.$ DIBICO $^{\circledR}$ ) suplementado con $100 \mathrm{mg} / \mathrm{L}$ de Ltriptófano $\left(\operatorname{Sigma}^{\circledR}\right.$ ), a $30 \pm 2^{\circ} \mathrm{C}$ por 5 días y $120 \mathrm{rpm}$ de agitación (de los Santos-Villalobos et al., 2013, p. 615). Posteriormente, los cultivos celulares fueron centrifugados (4000 rpm durante 10 $\mathrm{min}$ ), y los sobrenadantes reaccionaron individualmente en oscuridad por $30 \mathrm{~min}$ con el reactivo de Salkowski (4.5g de $\mathrm{FeCl}_{3}\left(\mathrm{FagaLab}^{\circledR}\right)$ en $\mathrm{H}_{2} \mathrm{SO}_{4}$ (J.T. Baker $\left.{ }^{\circledR}\right) 10.8 \mathrm{M}$ ), en una relación 2:1 (reactivo-muestra), para determinar la concentración de indoles acorde al método colorimétrico de Glickmann \& Dessaux (1995, p. 793). La formación de un color rosado indicó la producción de indoles, la cual se cuantificó por espectrofotometría a 540nm (BioTek ${ }^{\circledR}$ ELx800). Las 
concentraciones de indoles producidas fueron estimadas con una curva patrón de AIA (Sigma ${ }^{\circledR}$ ), en un rango de $2-50 \mu \mathrm{g} / \mathrm{ml}$. Los ensayos se realizaron por triplicado

Solubilización de fósforo insoluble. Las cepas fueron inoculadas por triplicado usando $10 \mu \mathrm{L}$ de una suspensión de $1 \times 10^{6}$ células/mL en cajas de Petri conteniendo Agar Pikovskaya (PVK), suplementado con azul de bromofenol $\left(\mathrm{C}_{19} \mathrm{H}_{10} \mathrm{Br}_{4} \mathrm{O}_{5} \mathrm{~S}\right)\left(\mathrm{Jalmek}^{\circledR}\right)$ y fosfato tricálcico (Biobasic ${ }^{\circledR}$ ) como fuente insoluble de fósforo (Glucosa $\left(\mathrm{Jalmek}^{\circledR}\right) 10.0 \mathrm{~g} / \mathrm{L}, \mathrm{Ca}_{3}\left(\mathrm{PO}_{4}\right)_{2} 5.0 \mathrm{~g} / \mathrm{L},\left(\mathrm{NH}_{4}\right)_{2} \mathrm{SO}_{4}$ $\left(\mathrm{Jalmek}^{\circledR}\right) 0.5 \mathrm{~g} / \mathrm{L}, \mathrm{NaCl}\left(\right.$ Biobasic $\left.^{\circledR}\right) 0.2 \mathrm{~g} / \mathrm{L}, \mathrm{MgSO}_{4}-7 \mathrm{H}_{2} \mathrm{O}\left(\mathrm{Jalmek}^{\circledR}\right) 0.1 \mathrm{~g} / \mathrm{L}, \mathrm{KCl}\left(\mathrm{Jalmek}^{\circledR}\right.$ ) $0.2 \mathrm{~g} / \mathrm{L}$, extracto de levadura $\left(\mathrm{DIBICO}^{\circledR}\right) 0.5 \mathrm{~g} / \mathrm{L}, \mathrm{MnSO}_{4}-\mathrm{H}_{2} \mathrm{O}\left(\mathrm{Jalmek}^{\circledR}\right) 0.002 \mathrm{~g} / \mathrm{L}, \mathrm{FeSO}_{4}-$ $7 \mathrm{H}_{2} \mathrm{O}\left(\right.$ Jalmek $\left.^{\circledR}\right) 0.002 \mathrm{~g} / \mathrm{L}$, Agar $\left(\right.$ DIBICO $\left.^{\circledR}\right) 15.0 \mathrm{~g} / \mathrm{L}$, azul de bromofenol $0.025 \mathrm{~g} / \mathrm{L}$, y pH 7.0) (Pikovskaya, 1948, 315). La capacidad de las cepas para solubilizar fosfatos fue positiva con base en la formación de un halo transparente, después de 7 días de incubación a $28 \pm 2^{\circ} \mathrm{C}$ (Onyia \& Anyanwu, 2013, p. 52).

Producción de sideróforos. El ensayo para detectar la producción de sideróforos por las bacterias estudiadas fue descrito por Alexander and Zuberer, (1991, p. 39), utilizando el Agar Chrome Azurol S (CAS). Este fue preparado mezclando cuidadosamente 4 soluciones, teniendo la siguiente composición, Solución 1: $10 \mathrm{~mL}$ de $1 \mathrm{mM} \mathrm{FeCl}_{3}$ (disueltos en $1 \mathrm{mM} \mathrm{HCl}$ ) y $50 \mathrm{~mL}$ de CAS (Sigma $\left.{ }^{\circledR}\right)(1.21 \mathrm{mg} / \mathrm{mL})$ fueron añadidos por separado a $40 \mathrm{~mL}$ de HDTMA (Sigma ${ }^{\circledR}$ ) $\left(1.82 \mathrm{mg} / \mathrm{mL}\right.$ ). Solución 2: $30.24 \mathrm{~g}$ de PIPES (Sigma ${ }^{\circledR}$ ) fueron disuelto en $750 \mathrm{~mL}$ de solución salina $\left(0.3 \mathrm{~g} \mathrm{KH}_{2} \mathrm{PO}_{4}\left(\mathrm{FagaLab}^{\circledR}\right), 0.5 \mathrm{~g} \mathrm{NaCl}\right.$ y $1 \mathrm{~g} \mathrm{NH}_{4} \mathrm{Cl}\left(\mathrm{Jalmek}^{\circledR}\right)$ ), el pH fue ajustado a 6.8 con $\mathrm{KOH}\left(\right.$ Jalmek $^{\circledR}$ ) al $50 \%$, el volumen se ajustó a $800 \mathrm{~mL}$, y después $15 \mathrm{~g}$ de agar bacteriológico $\left(\right.$ DIBICO $^{\circledR}$ ) fueron añadido. Solución 3: 2 g glucosa, 2 g manitol (Jalmek ${ }^{\circledR}$ ), 493 $\mathrm{mg} \mathrm{MgSO}_{4}, 11 \mathrm{mg} \mathrm{CaCl}_{2}\left(\mathrm{Jalmek}^{\circledR}\right), 1.17 \mathrm{mg} \mathrm{MnSO}_{4}, 1.4 \mathrm{mg} \mathrm{H}_{3} \mathrm{BO}_{3}\left(\mathrm{Jalmek}^{\circledR}\right), 0.04 \mathrm{mg} \mathrm{CuSO}_{4}$ $\left(\mathrm{FagaLab}^{\circledR}\right)$, $1.2 \mathrm{mg} \mathrm{ZnSO}_{4}\left(\mathrm{FagaLab}^{\circledR}\right)$, y $1 \mathrm{mg} \mathrm{Na} \mathrm{MoO}_{4}\left(\mathrm{Jalmek}^{\circledR}\right)$ se disolvieron en $70 \mathrm{~mL}$ de agua destilada. Solución 4: se filtraron $30 \mathrm{~mL}$ de casamino ácidos (USBiological ${ }^{\circledR}$ ) al $10 \%(1$ $\mathrm{mg} / \mathrm{mL}$ ). El medio de cultivo se inoculó con $10 \mu \mathrm{L}$ de una suspensión celular de $1 \times 10^{6}$ células $/ \mathrm{mL}$, y se incubó a $28 \pm 2{ }^{\circ} \mathrm{C}$ por 7 días. La formación de un halo color naranja-amarillo confirmó la producción de sideróforos por las cepas estudiadas (Patel et al., 2018, p. 81). Los ensayos se realizaron por triplicado.

La capacidad de las cepas de estudio para producir sideróforos y solubilizar fósforo inorgánico se categorizó en 3 niveles: bajo $(<1)$; intermedio (entre 1 y 2); o alto $(>2)$ (Marra et 
al., 2013, p. 603), y se determinó el índice de solubilización de fósforo insoluble (IS) y el índice de producción de sideróforos (IP) mediante la siguiente fórmula:

$$
I S \text { o IP }=\frac{\text { diametro halo }(\mathrm{mm})}{\text { diametro colonia }(\mathrm{mm})}
$$

\section{Promoción del crecimiento por las RPCV estudiadas, en cámara de crecimiento}

La capacidad de las cepas TE3 ${ }^{\mathrm{T}}$, TRQ8 y TRQ65 para promover el crecimiento vegetal fue evaluada utilizando como planta modelo el trigo variedad CIRNO C2008. El ensayo de interacción planta x RPCV se llevó a cabo en una cámara de crecimiento (BJPX-A450, BIOBASE $^{\circledR}$ ), simulando condiciones de campo registradas en el Valle de Yaqui (13 h oscuridad a $14^{\circ} \mathrm{C}, 2 \mathrm{~h}$ luz a $18^{\circ} \mathrm{C}, 7 \mathrm{~h}$ luz a $25^{\circ} \mathrm{C}$ y $2 \mathrm{~h}$ luz a $18^{\circ} \mathrm{C}$ ), durante los últimos 3 años por la estación del clima REMAS $\left(27^{\circ} 22^{\prime} 12.28^{\prime \prime} \mathrm{N}\right.$ y $\left.109^{\circ} 55^{\prime} 51.71^{\prime \prime} \mathrm{O}\right)$. Para esto, 250 semillas de trigo fueron desinfectadas previamente esterilizando la superficie con $1.5 \%(\mathrm{v} / \mathrm{v})$ con hipoclorito de sodio ( $\mathrm{NaClO}$ ) por $10 \mathrm{~min}$, y 3 lavados con agua destilada estéril (Grobelak et al., 2015, p. 22). Las semillas desinfectadas fueron germinadas en toallas de papel húmedas $(50 \times 25 \mathrm{~cm})$ enrolladas (ISTA, 1985) y transferidas asépticamente a charolas forestales (diámetro de cavidad $4.7 \mathrm{~cm}$ ) que contenían 190 gramos de una mezcla de suelo estéril y perlita (esterilizados por 5 días consecutivos a $121^{\circ} \mathrm{C}-15 \mathrm{lb} / \mathrm{in}^{2}$ por $1 \mathrm{~h}$ ), en una relación 70:30. Los pre-inóculos bacterianos fueron cultivados en tubos Falcon $(50 \mathrm{~mL})$ con $10 \mathrm{~mL}$ de CN, e incubados a $28^{\circ} \mathrm{C}$ por $24 \mathrm{~h}$ en agitación continua (120 rpm). Para la preparación del inóculo se tomó $1 \mathrm{~mL}\left(1 \times 10^{6}\right.$ células $\left./ \mathrm{mL}\right)$ del pre-inóculo y se inoculó en $200 \mathrm{~mL}$ de $\mathrm{CN}$ contenidos en un matraz Erlenmeyer (1 L), e incubado bajo las condiciones mencionadas con anterioridad. Una vez que se cumplió el tiempo de incubación, se procedió a centrifugar la suspensión bacteriana a $3500 \mathrm{rpm}$ por $15 \mathrm{~min}$, la biomasa obtenida se lavó 2 veces con agua destilada estéril y se ajustó la densidad celular a una concentración de $1 \times 10^{6}$ células $/ \mathrm{mL}$ (Valenzuela-Aragon et al., 2018).

Finalmente, $1 \mathrm{~mL}\left(1 \times 10^{6}\right.$ células $\left./ \mathrm{mL}\right)$ de cada cepa bacteriana fue inoculado a cada plántula de trigo. Se realizó un diseño experimental aleatorio y se evaluaron 8 tratamientos con las cepas individuales y las interacciones entre éstas: 1) TE3 ${ }^{\mathrm{T}}$; 2) TRQ65; 3) TRQ8; 4) TE3 ${ }^{\mathrm{T}}$ TRQ65; 5) TE3 ${ }^{\mathrm{T}}$-TRQ8; 6) TRQ65-TRQ8; 7) CS3 (consorcio formado por las 3 cepas); y 8) un tratamiento control (plántulas sin inocular). Se realizaron 2 réplicas biológicas, cada una con 15 
Promoción de crecimiento en trigo (Triticum turgidum L. subsp. durum) por la co-inoculación de cepas nativas de Bacillus aisladas del Valle del Yaqui, México

plántulas para cada tratamiento. Después de 45 días de la inoculación (etapa GS14 de la escala Zadoks), se procedió a la medición de parámetros morfométricos en las plantas de trigo, como: la longitud aérea (LA) y de raíz (LR); peso seco aéreo (PSA) y de raíz (PSR); e índice de biovolumen $(\mathrm{IB}=$ circunferencia*longitud aérea $)$.

\section{Análisis estadístico}

Los datos fueron analizados utilizando el análisis de varianza ANOVA y Tukey HSD ( $\mathrm{P} \geq 0.05)$ empleando el software estadístico Statistica 10 para Windows ${ }^{\circledR}$.

\section{$\underline{\text { Resultados }}$}

\section{Identificación molecular de las cepas bacterianas estudiadas}

Basados en la secuenciación del gen 16S ARNr, la cepa TRQ8 fue afiliada taxonómicamente a $B$. megaterium (cobertura 100\% e identidad 99.66\%) (Robles-Montoya et al., 2019); TRQ65 a $B$. paralicheniformis (cobertura 100\% e identidad 90.91\%) (Valenzuela-Ruiz et al., 2019); y TE3 ${ }^{\mathrm{T}}$ a B. cabrialesii (cobertura 100\% e identidad 100\%) (de los Santos Villalobos et al., 2019). Adicionalmente, en la Fig. 1 se muestra un árbol filogenético en el que se expresan las relaciones de similitud y disimilitud que existen entre las cepas en estudio. Las secuencias relacionadas taxonómicamente se agrupan en clados, lo cual es sustentado por el valor de bootstrap [el porcentaje en el que un clado se repite en 1000 simulaciones al azar (iteraciones)]. La configuración de un clado se considera fiable si presenta un bootstrap mayor a 50. Así, los valores de $62 \%$ para $B$. megaterium TRQ8, B. paralicheniformis TRQ65 con 98\%, y $B$. cabrialesii $\mathrm{TE}^{\mathrm{T}}$ con $9574 \%$ sustentan la afiliación taxonómica en el presente estudio. 


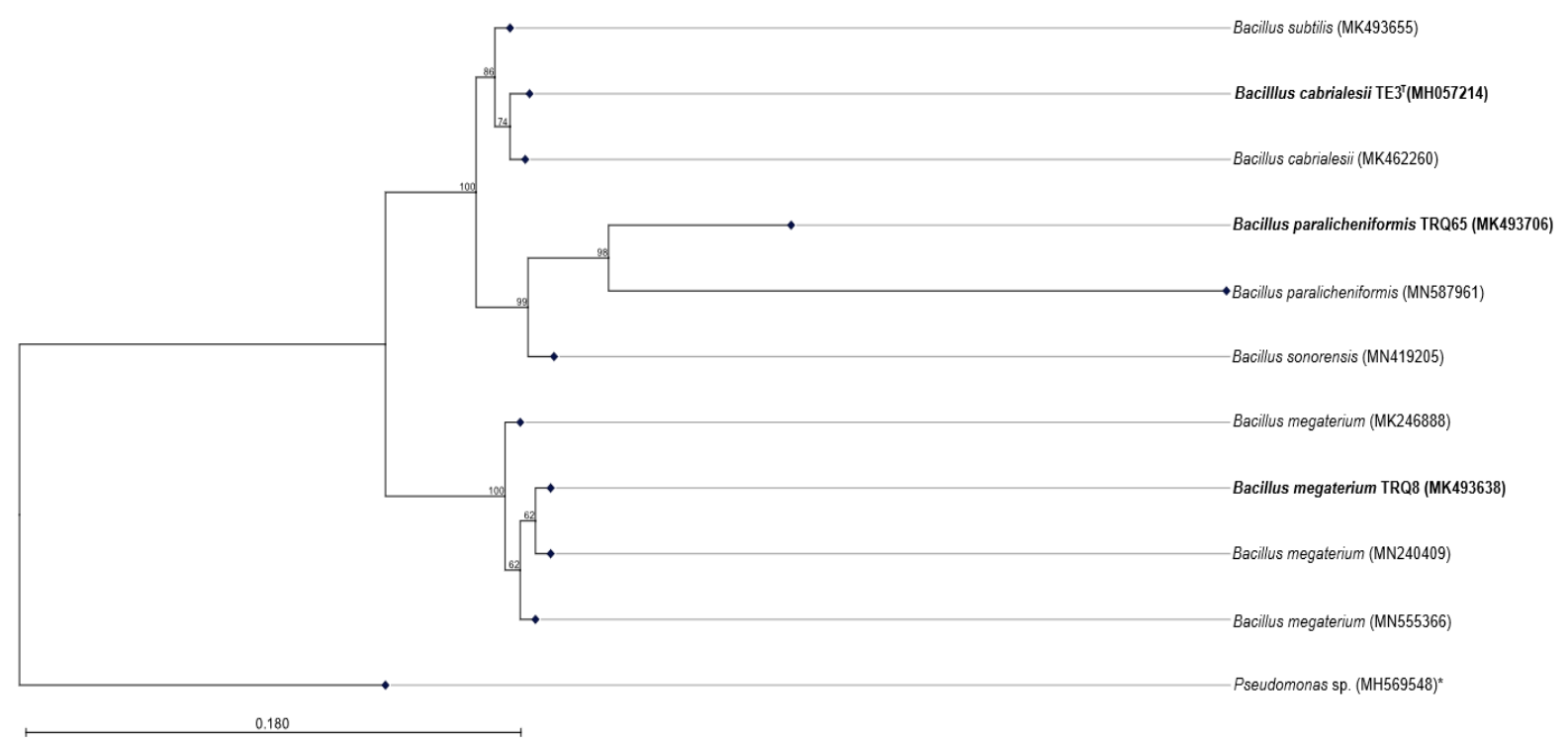

Fig. 1. Árbol filogenético construido con las secuencias del gen 16S ARNr de las cepas en estudio, utilizando el modelo Kimura 80 y Neighbor-Joining. Los agrupamientos se determinaron con 1000 iteraciones (bootstrap).

*Indica la secuencia outgroup (Pseudomonas sp. MH569548).

Fig. 1. Phylogenetic tree constructed with $16 \mathrm{~S}$ rRNA gene sequences of studied strains, using the Kimura80 and Neighbor-Joining model. The clusters were determined with 1000 iterations (bootstrap).

*Indicates the outgroup sequence (Pseudomonas sp. MH569548).

Por otra parte, las características morfológicas macro y microscópicas de las cepas en estudio se presentan en la Tabla 1, las cuales se distinguen por la forma de bacilo Gram positivo. Además, la capacidad de producir esporas es una de las características del género Bacillus y comúnmente deseada para su producción a nivel industrial.

Tabla 1.Características morfológicas de las tres rizobacterias promotoras del crecimiento vegetal.

Table 1. Morphological traits of the three studied plant growth-promoting rhizobacteria.

\begin{tabular}{|c|c|c|c|c|c|}
\hline Cepa & Afiliación taxonómica & $\begin{array}{l}\text { Numero de } \\
\text { Accesión }\end{array}$ & Características Macroscópicas & $\begin{array}{l}\text { Características } \\
\text { Microscópicas }\end{array}$ & $\begin{array}{c}\text { Reacción } \\
\text { GRAM }\end{array}$ \\
\hline TRQ8 & Bacillus megaterium & MK493638 & $\begin{array}{c}\text { Circular con borde entero y } \\
\text { elevación convexa }\end{array}$ & Bacilo & Gram + \\
\hline TRQ65 & Bacillus paralicheniformis & MK493706 & $\begin{array}{l}\text { Irregular con borde ondulado y } \\
\text { elevación plana }\end{array}$ & Bacilo & Gram + \\
\hline $\mathbf{T E 3}^{\mathrm{T}}$ & Bacillus cabrialesii & MH057214 & $\begin{array}{c}\text { Irregular con borde lobulado y } \\
\text { elevación plana }\end{array}$ & Bacilo & Gram + \\
\hline
\end{tabular}


Promoción de crecimiento en trigo (Triticum turgidum L. subsp. durum) por la co-inoculación de cepas nativas de Bacillus aisladas del Valle del Yaqui, México

\section{Caracterización metabólica de las RPCV in vitro}

Las cepas estudiadas mostraron la capacidad de producir indoles, siendo la cepa $B$. paralicheniformis TRQ65 la que produjo la mayor concentración $\left(39.29 \mu \mathrm{g} \mathrm{mL}^{-1}\right)$, seguida por $B$. megaterium TRQ8 y B. cabrialesii $\mathrm{TE}^{\mathrm{T}}$ (Tabla 2). Similarmente, las 3 cepas mostraron la capacidad de solubilizar el fósforo insoluble, sin observar diferencias significativas $(\mathrm{P} \geq 0.05)$ entre ellas. Sin embargo, sólo la cepa TRQ8 fue capaz de producir sideróforos $(\mathrm{IP}=8.17)($ Tabla 2).

Tabla 2. Caracterización metabólica in vitro de las tres rizobacterias promotoras del crecimiento vegetal estudiadas.

Table 2. In vitro metabolic characterization of the three studied plant growth-promoting rhizobacteria.

\begin{tabular}{|c|c|c|c|c|}
\hline Cepa & Afiliación taxonómica & $\begin{array}{c}\text { Producción de } \\
\text { índoles }\left(\mu \mathrm{g} \mathrm{mL}^{-1}\right)\end{array}$ & $\begin{array}{c}\text { Solubilización de } \\
\text { fosfatos (IS) }\end{array}$ & $\begin{array}{l}\text { Producción de } \\
\text { sideróforos (IP) }\end{array}$ \\
\hline TRQ8 & Bacillus megaterium & $12.03 \pm 1.93^{b}$ & $1.38 \pm 0.04^{\mathrm{a}}$ & $8.17 \pm 0.01$ \\
\hline TRQ65 & $\begin{array}{l}\text { Bacillus } \\
\text { paralicheniformis }\end{array}$ & $39.29 \pm 0.30^{\mathrm{a}}$ & $1.37 \pm 0.05^{\mathrm{a}}$ & -- \\
\hline $\mathbf{T E 3}^{\mathrm{T}}$ & Bacillus cabrialesii & $8.21 \pm 1.35^{\mathrm{c}}$ & $1.43 \pm 0.04^{\mathrm{a}}$ & -- \\
\hline
\end{tabular}

Medias $(n=3)$ en la misma columna con la misma letra no presentan diferencias significativas, según la prueba de Tukey HSD $(\mathrm{P} \geq 0.05)$. Las variaciones corresponden a la desviación estándar.

Means $(\mathrm{n}=3)$ in the same column with the same letter do not show significant differences, according to the Tukey HSD test $(\mathrm{P} \geq 0.05)$. The variations correspond to the standard deviation.

\section{Promoción del crecimiento en el trigo por las RPCV, en cámara de crecimiento}

El consorcio de las cepas TRQ65+TRQ8 presentaron diferencia significativa positiva sobre las plantas de trigo comparadas con el control (no inoculado), en las 5 variables analizadas (longitud aérea, longitud de raíz, peso seco aéreo, peso seco de raíz, e índice de biovolumen), la longitud aérea y de raíz mostraron un incremento de $6 \%$ y $10 \%$, respectivamente; mientras que el peso seco aéreo se incrementó en 60\%, y el peso seco radicular mostró 82\% de incremento (Fig. 2). El índice de biovolumen de las plantas inoculadas por este consorcio bacteriano (TRQ65 + TRQ8), presentó un incremento de $18 \%$, en comparación con el control. Por otra parte, el consorcio TRQ8+TE3 ${ }^{\mathrm{T}}$ mostró diferencia significativa positivas respecto del tratamiento control en las variables peso seco aéreo, peso seco de raíz e índice de biovolumen $(25 \%, 44 \%$ y $18 \%)$, respectivamente. Por lo que respecta al consorcio TE3 ${ }^{\mathrm{T}}+\mathrm{TRQ} 65$, ninguna diferencia significativa fue observada en las variables analizadas, en contraste con las plantas no inoculadas (control). 
El consorcio de las 3 cepas bacterianas (TRQ8 + TRQ65 + TE3 ${ }^{\mathrm{T}}$ ) mostró una tendencia a incrementar el valor de cuatro de las variables estudiadas (LA, PSA, PSR e IB); sin embargo, no se observaron diferencias significativas en comparación con el tratamiento control. Por otro lado, en los tratamientos de inoculación individual, la cepa TRQ8 mostró el mayor incremento significativo (39\%) con respecto al control para la biomasa seca aérea. Lo anterior evidencia que el efecto de promoción de crecimiento más importante fue debido a la inoculación de las cepas TRQ65+TRQ8.

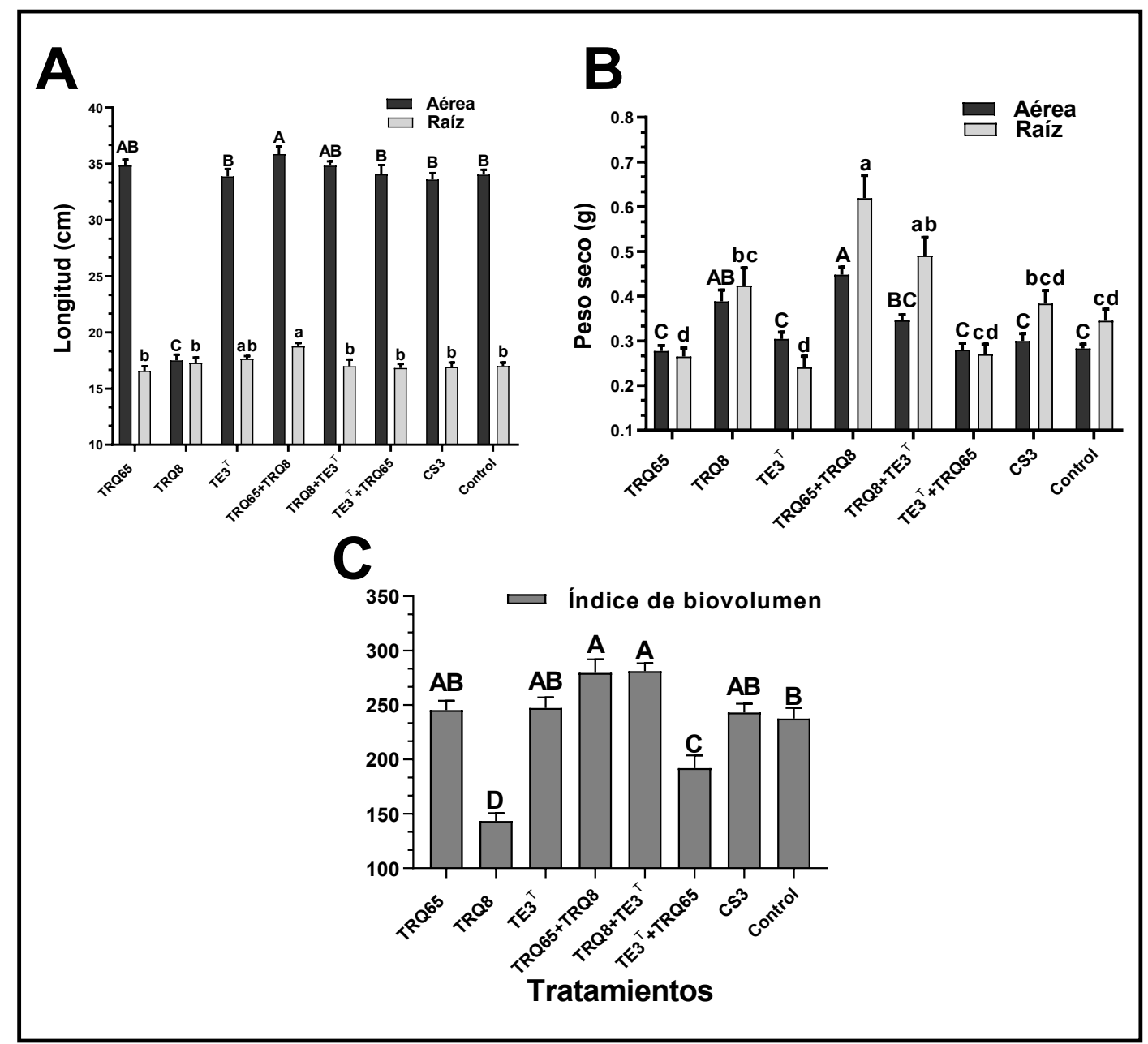

Fig. 2. Efecto de la inoculación de las cepas estudiadas (individuales o en consorcios) sobre (A) Longitud aérea y de raíz; (B) Peso seco aéreo y de raíz; y (C) Índice de biovolumen (circunferencia $\mathrm{x}$ longitud), bajo condiciones de cámara de crecimiento. Las literales indican diferencia significativa acorde con Tukey HSD $(\mathrm{P}<0.05)$.

Fig. 2. Effect of inoculation of the studied strains (individual or consortia) on (A) Aerial and radical length; (B) Aerial and radical dry weight; and (C) Biovolume index (circumference $\mathrm{x}$ length), under growth chamber conditions. The literals indicate significant differences according to Tukey HSD $(\mathrm{P}<0.05)$. 
Promoción de crecimiento en trigo (Triticum turgidum L. subsp. durum) por la co-inoculación de cepas nativas de Bacillus aisladas del Valle del Yaqui, México

\section{Discusión y Conclusiones}

Las cepas bacterianas estudiadas, mediante la secuenciación del gen 16S ARNr, fueron afiliadas taxonómicamente al género Bacillus; específicamente, la cepa TRQ8 a B. megaterium; la cepa TE3 $^{\mathrm{T}}$ a B. cabrialesii; y la cepa TRQ65 a B. paralicheniformis (Tabla 1 y Fig. 1). Esta afiliación taxonómica fue soportada por las características macro y microscópicas de las cepas, relacionadas al género Bacillus (Tabla 1), tanto en morfología colonial como celular (Heyrman et al., 2009, p. 193). El género Bacillus es ampliamente utilizado en la biotecnología agrícola, donde el $85 \%$ de los inoculantes microbianos que actualmente se comercializan incluyen cepas de este género en su composición, debido a su amplia versatilidad metabólica (Villarreal-Delgado et al., 2018, p. 95)

Diversas cepas de las especies mencionadas anteriormente han sido reportadas como BPCV promisorias. B. megaterium ha mostrado la capacidad de regular el crecimiento en el cultivo de trigo, mejorando significativamente variables morfométricas, como longitud de raíz (68.4\%) y peso seco (>50\%), con respecto a plantas no inoculadas (Robles-Montoya et al., 2019, p. 201), y producir polihidroxibutirato $(46.79 \%$ en un medio de cultivo con $1 \%$ de etanol), un metabolito de reserva involucrado en la competencia de las bacterias bajo condiciones de estrés (Aguirre et al., 2017, p. 24; Sanches-Santos et al., 2017, p. 1855); B. cabrialesii es una nueva especie recién reportada (de los Santos Villalobos et al., 2019) y los trabajos con esta nueva especie bacteriana están siendo desarrollados. Sin embargo, su relación filogenética con $B$. subtilis es la más alta y este género de bacteria ha sido estudiado por su capacidad promotora del crecimiento vegetal en cultivos de tomate y trigo obteniendo incrementos en la longitud de raíz (5.2\% y 5.6\%, respectivamente), así como en el peso seco de raíz y parte aérea con un aumento de $60 \%$ y $45 \%$ respectivamente para cada cultivo, debido posiblemente por la solubilización de fósforo y producción de índoles (Valenzuela-Aragon et al., 2018; Walia et al., 2014, p. 145), así como por su capacidad como agente de control biológico contra Bipolaris sorokiniana, mostrando 98\% de inhibición de crecimiento de dicho patógeno (Villa-Rodriguez, et al., 2019, p. 135); mientras que B. paralicheniformis ha sido reportado como promotora del crecimiento vegetal, promoviendo un aumento de la biomasa seca total (17.8\%), índice de biovolumen (41\%), y aumento de nutrientes $(34 \% \mathrm{~N}, 18 \% \mathrm{P}$, y $29 \% \mathrm{~K})$ en el cultivo de Capsicum annuum (Thilagar et al., 2018, p. 813), eso fue atribuido a la solubilización de fosfatos y la producción de fitohormonas, como AIA (Angulo et al., 2014, p. 338; Valenzuela-Aragon et al., 2018). 
Además, diversas especies del género Bacillus se caracterizan por ser ubicuos, encontrándose principalmente como bacterias rizosféricas o endófitas asociadas a distintos cultivos agrícolas, incluido el trigo (Khalid et al., 2004, p. 2303; Akinrinlola et al., 2018, p. 1; de los Santos-Villalobos, 2018, p. 191). Lo anterior es atribuido a su capacidad de formar endosporas, y colonizar las plantas mediante la producción de sustancias antimicrobianas contra otros competidores (Valenzuela-Aragon et al., 2018). Adicionalmente, el género Bacillus es ampliamente reportado como RPCV del crecimiento vegetal y puede ser utilizado de manera individual o en co-inoculación con otros géneros bacterianos. Por ejemplo, B. licheniformis 255 (cepa solubilizadora de fosfatos) incrementa la concentración de fósforo disponible en el suelo cuando es co-inoculada con Rhizobium pisi en Cytisus striatus y Lupinus luteus (BalseiroRomero et al., 2017, p. 676).

Las RPCV pertenecientes al género Bacillus actúan mediante diversos mecanismos, como la producción de fitohormonas, la secreción de antibióticos, la inducción de resistencia sistémica, producción de enzimas líticas de la pared celular de patógenos (Ghosh, Gupta, \& Mohapatra, 2019; Villarreal-Delgado et al., 2018, p. 95; Won et al., 2019, p. 8). De esta manera, es determinante estudiar los potenciales mecanismos de promoción de crecimiento vegetal de las cepas promisorias, ya que éste es considerado uno de los criterios previos para conocer la interacción de las cepas bacterianas con las plantas. En el presente estudio, las 3 cepas bacterianas mostraron la capacidad para producir indoles (8.21 a $39.29 \mu \mathrm{g} / \mathrm{mL}$ ) (Tabla 2), observando la mayor producción $(39.29 \mu \mathrm{g} / \mathrm{mL})$ por la cepa TRQ65. La elaboración de compuestos indólicos por bacterias ha mostrado un efecto sobre el balance hormonal en las plantas, y, por lo tanto, influye en su crecimiento (Govindasamy et al., 2009, p. 71; He et al., 2017, p. 1180). Así, los compuestos indólicos producidos por RPCV, y en específico por el género Bacillus, han sido asociados a la interacción planta-microorganismo, y su actividad promotora del crecimiento radicular y foliar en las plantas (Ali et al., 2009, p. 519).

Además, las cepas estudiadas mostraron índices de solubilización de fósforo (Tabla 2) en un rango de 1.37 a 1.43, siendo la cepa $B$. subtilis quien manifestó el mayor valor. Hasta la fecha, se han descrito diversas especies bacterianas con la capacidad de solubilizar fósforo inorgánico insoluble (Corrales et al., 2014), pertenecientes a los géneros Pseudomonas, Bacillus, Rhizobium, Burkholderia, Achromobacter, Agrobacterium, Micrococcus, Aerobacter, Flavobacterium y Erwinia (Chen et al., 2006, p. 33; Paredes \& Espinosa, 2010, p. 61). Lo anterior ha sido 
Promoción de crecimiento en trigo (Triticum turgidum L. subsp. durum) por la co-inoculación de cepas nativas de Bacillus aisladas del Valle del Yaqui, México

evidenciado por la capacidad de las cepas bacterianas para producir ácidos orgánicos, y la actividad de fitasas (mio-inositol hexakisfosfato fosfohidrolasas) para mineralizar fitatos (Idriss et al., 2002, p. 2097; Jorquera et al, 2008, p. 1025; Kumar et al., 2013, p. 1361; Richardson \& Simpson, 2011, p. 989; Singh et al., 2014, p. 2981).

Por otra parte, distintos reportes han confirmado que la producción de sideróforos por cepas bacterias impacta significativamente la asimilación de varios metales, incluyendo $\mathrm{Fe}, \mathrm{Zn}$, y Cu para las plantas (Egamberdiyeva and Höflich, 2004, p. 293; Antoun, 2013, p. 353; Patel et al., 2018, p. 81); así como la supresión del crecimiento de organismos patógenos (Carrillo-Castañeda et al., 2005, p. 1853; Joseph et al., 2007, p. 141; Wahyudi et al., 2011, p. 34). B. megaterium TRQ8 fue la única cepa que mostró la capacidad de producir sideróforos $(\mathrm{IP}=8.18)$, cuando se inoculó en el medio Agar CAS (de los Santos-Villalobos et al., 2012, p. 2615).

La función promotora del crecimiento vegetal de las cepas TRQ8, TRQ65, y TE3 ${ }^{\mathrm{T}}$ fue estudiado por su inoculación en plantas de trigo. En comparación con el tratamiento control, la co-inoculación de las cepas TRQ65+TRQ8 presentó diferencia significativa $(p<0.05)$ en todas las variables morfométricas analizadas en el cultivo, como lo indicaron estas variables: $\mathrm{LA}=5.5 \%$, $\mathrm{LR}=10.5 \%, \mathrm{PSA}=60.7 \%, \mathrm{PSR}=82-3 \%$ e IB $=17.6 \%$ (Fig. 2). La co-inoculación de $B$. paralicheniformis TRQ65 y B. megaterium TRQ8 mostró un incremento en la longitud y peso seco de la planta de trigo, y en el índice de biovolumen, lo cual sugiere una movilización incrementada de nutrientes en la planta (Thilagar et al., 2018, p. 813). El comportamiento anteriormente descrito, fue observado por la inoculación en consorcio de las cepas TRQ8 y TRQ65; sin embargo, la inoculación de dichas cepas individualmente al cultivo de trigo no mostró diferencias significativas en comparación con las plantas no inoculadas, e incluso la inoculación de TRQ8 disminuyó en un 90\% la longitud aérea, 65\% el índice de biovolumen; mientras que la inoculación de TRQ65 redujo el peso seco aéreo y de raíz en un 3\% y 30\%, respectivamente.

Diversos estudios han evidenciado que las capacidades de las RPCV mejoran cuando son inoculadas en consorcio (Brenner et al., 2008, p. 484). Por ejemplo, Dary et al. (2010, p. 323) y Malboobi et al. (2009, p. 1479) demostraron que la inoculación de consorcios binarios de RPCV como P. putida P13, P. agglomerans P5, Bradyrhizobium sp.750 y Pseudomonas sp. Az13, a plantas de Solanum tuberosum y Lupinus luteus, tienen a mayor promoción del crecimiento vegetal en variables como peso seco de raíz, peso seco aéreo, contenido de nitrógeno y 
rendimiento final en el caso de $S$. tuberosum, que una cepa individual; esto debido a que al combinar bacterias con distintas capacidades metabólicas ocurre un efecto sinérgico en la utilización simultanea de compuestos orgánicos, e inorgánicos que se encuentran en el suelo. Dicho efecto sinérgico fue observado en el presente estudio, donde por influencia de la inoculación del consorcio binario B. megaterium TRQ8 y B. paralicheniformis TRQ65, hubo incrementos significativos en todas las variables morfométricas analizadas (LA, LR, PSA, PSR e IB) con respecto al tratamiento control y a las cepas inoculadas individualmente.

La aplicación de consorcios bacterianos, específicamente binarios y ternarios del estudio mostró un impacto positivo en las variables analizadas a la planta, lo cual refuerza lo mencionado por Brenner et al. (2008) quienes mencionan que las poblaciones mixtas pueden realizar funciones que son difíciles e incluso imposibles para cepas individuales. El consorcio binario conformado por las cepas TRQ8 + TRQ65 mostró que sus características de promoción en conjunto pueden lograr un resultado deseado, en comparación con los resultados del consorcio de las 3 cepas bacterianas. El empleo de un consorcio microbiano ha demostrado que entre los involucrados tienen que equilibrar dos o más tareas para que se complementen eficientemente dentro de un sistema, y esto plantea en ocasiones desafíos insuperables, cuando se trata de la aplicación de 3 o más MOOS con características similares (Keller y Surette, 2006; Eiteman et al., 2008; Lynd et al., 2002; Brenner et al., 2008). Por ejemplo, durante la limitación de nutrientes una población minoritaria puede convertirse en la población más activa, si posee una actividad metabólica de la que depende la supervivencia de todo el consorcio (LaPara et al., 2002; Boopathy et al., 2015). Sin embargo, una gran cantidad de cepas o especies en un corsorcio no garantiza la supervivencia, ni el efecto promotor deseado.

Finalmente, con el presente estudio se concluye que las bacterias nativas del Valle del Yaqui, asociadas al cultivo de trigo, tienen la capacidad de promover el crecimiento de este cereal, en estadios tempranos de la planta. El efecto promotor del crecimiento vegetal por las cepas estudiadas se incrementó por su inoculación en consorcio (B. megaterium TRQ8 + Bacillus paralicheniformis TRQ65), a las plantas de trigo. Por lo cual, futuros estudios deben ser desarrollados para entender la ecología de dicho consorcio bacteriano, y la interacción con el sistema suelo-planta. Esto con el objetivo de incrementar el conocimiento sobre sus mecanismos de acción, y la regulación de éstos bajo las condiciones bióticas y abióticas de los 
Promoción de crecimiento en trigo (Triticum turgidum L. subsp. durum) por la co-inoculación de cepas nativas de Bacillus aisladas del Valle del Yaqui, México

agroecosistemas. Lo cual permitiría el uso de dichas cepas en campo, sin efectos adversos químico-biológicos al ambiente.

\section{$\underline{\text { Agradecimientos }}$}

Los autores agradecen el apoyo recibido por el Consejo Nacional de Ciencia y Tecnología (CONACyT) mediante el financiamiento de los proyectos 253663 y 257246 . Finalmente, Jonathan Rojas Padilla CVU 262903, Luis Abraham Chaparro Encinas CVU 539689 y Rosa Isela Robles Montoya CVU 627262, agradecen al CONACYT por la beca otorgada para sus estudios de posgrado.

\section{$\underline{\text { Referencias }}$}

Aguirre, J. B. R., Gómez, L. Z. O., Villalobos, S. D. L. S., \& Sánchez, M. L. (2017). Production of polyhydroxybutyrate from milk whey fermentation by Bacillus Production of polyhydroxybutyrate from milk whey fermentation by Bacillus megaterium TRQ8. Revista Latinoamericana de Recursos Naturales, 13(1), 24-31.

Akinrinlola, R. J., Yuen, G. Y., Drijber, R. A., \& Adesemoye, A. O. (2018). Evaluation of Bacillus Strains for Plant Growth Promotion and Predictability of Efficacy by in vitro Physiological Traits. International Journal of Microbiology, 1-11. DOI: https://doi.org/10.1155/2018/5686874.

Alexander, D. B., \& Zuberer, D. A. (1991). Use of chrome azurol S reagents to evaluate siderophore production by rhizosphere bacteria. Biology and Fertility of Soils, 12(1), 3945. DOI: https://doi.org/10.1007/BF00369386.

Ali, B., Sabri, A. N., Ljung, K., \& Hasnain, S. (2009). Quantification of indole-3-acetic acid from plant associated Bacillus spp. and their phytostimulatory effect on Vigna radiata (L.). World Journal of Microbiology and Biotechnology. DOI: https://doi.org/10.1007/s11274008-9918-9.

Altschul, S. F., Gish, W., Miller, W., Myers, E. W., \& Lipman, D. J. (1990). Basic local alignment search tool. Journal of Molecular Biology. DOI: https://doi.org/10.1016/S00222836(05)80360-2.

Angulo, V. C., Sanfuentes, E. A., Rodríguez, F., \& Sossa, Y. K. E. (2014). Caracterización de rizobacterias promotoras de crecimiento en plántulas de Eucalyptus nitens. Revista 
Argentina de Microbiologia, 46(4), 338-347. DOI: https://doi.org/10.1016/S03257541(14)70093-8.

Antoun, H. (2013). Plant-Growth-Promoting Rhizobacteria. Brenner's Encyclopedia of Genetics: Second Edition, 353-355. DOI: https://doi.org/10.1016/B978-0-12-374984-0.01169-4.

Asseng, S. (2015). Uncertainties of Climate Change Impacts in Agriculture. Procedia Environmental Sciences. DOI: https://doi.org/10.1016/j.proenv.2015.07.276.

Balseiro-Romero, M., Gkorezis, P., Kidd, P. S., Van Hamme, J., Weyens, N., Monterroso, C., \& Vangronsveld, J. (2017). Use of plant growth promoting bacterial strains to improve Cytisus striatus and Lupinus luteus development for potential application in phytoremediation. Science of The Total Environment, 581-582, 676-688. DOI: https://doi.org/10.1016/J.SCITOTENV.2016.12.180.

Borlaug, N. E. (1968). Wheat Breeding and its Impact on World Food Supply. Third International Wheat Genetics Symposium.

Boopathy, R., Kern, C., \& Corbin, A. (2015). Use of Bacillus consortium in waste digestion and pathogen control in shrimp aquaculture. International Biodeterioration \& Biodegradation, 102, 159-164. DOI:10.1016/j.ibiod.2015.02.001.

Brenner, K., You, L., \& Arnold, F. H. (2008). Engineering microbial consortia: a new frontier in synthetic biology. Trends in Biotechnology, 26(9), 483-489. DOI: https://doi.org/10.1016/j.tibtech.2008.05.004.

Bresler, M. M., Rosser, S. J., Basran, A., \& Bruce, N. C. (2000). Gene cloning and nucleotide sequencing and properties of a cocaine esterase from Rhodococcus sp. strain MB1. Applied and Environmental Microbiology, 66(3), 904-908. DOI: https://doi.org/10.1128/AEM.66.3.904-908.2000.

Bringhurst, R. M., Cardon, Z. G., \& Gage, D. J. (2001). Galactosides in the rhizosphere: Utilization by Sinorhizobium meliloti and development of a biosensor. Proceedings of the National Academy of Sciences. DOI: https://doi.org/10.1073/pnas.071375898.

Carrillo-Castañeda, G., Munoz, J. J., Peralta-Videa, J. R., Gomez, E., \& Gardea-Torresdey, J. L. (2005). Modulation of uptake and translocation of iron and copper from root to shoot in common bean by siderophore-producing microorganisms. Journal of Plant Nutrition. DOI: https://doi.org/10.1080/01904160500251340.

Cattelan, A. J., Hartel, P. G., \& Fuhrmann, J. J. (1999). Screening for Plant Growth-Promoting 
Promoción de crecimiento en trigo (Triticum turgidum L. subsp. durum) por la co-inoculación de cepas nativas de Bacillus aisladas del Valle del Yaqui, México

Rhizobacteria to Promote Early Soybean Growth. Soil Science Society of America Journal, 1670. DOI: https://doi.org/10.2136/sssaj1999.6361670x.

Chen, Y. P., Rekha, P. D., Arun, A. B., Shen, F. T., Lai, W. A., \& Young, C. C. (2006). Phosphate solubilizing bacteria from subtropical soil and their tricalcium phosphate solubilizing abilities. Applied Soil Ecology.

DOI: https://doi.org/10.1016/j.apsoil.2005.12.002

Corrales, L., Arévalo, Z., \& Moreno, V. (2014). Solubilización de fosfatos: una función microbiana importante en el desarrollo vegetal. Nova, 12(21), 67-79. DOI: https://doi.org/20026743.

Cortes-Jimenez, J. M., Troyo-Diéguez, E., Murillo-Amador, B., García-Hernández, J. L., Garatuza-Payán, J., \& Suh Lee, S. (2009). Índices de calidad del agua del acuífero del Valle del Yaqui, Sonora. Terra Latinoamericana, 27(2), 133-141. Retrieved from http://www.scielo.org.mx/scielo.php?script=sci_arttext\&pid=S0187-

$57792009000200006 \& \operatorname{lng}=\mathrm{es} \& n r m=$ iso \&tlng=es.

Dary, M., Chamber-Pérez, M. A., Palomares, A. J., \& Pajuelo, E. (2010). "In situ" phytostabilisation of heavy metal polluted soils using Lupinus luteus inoculated with metal resistant plant-growth promoting rhizobacteria. Journal of Hazardous Materials. DOI: https://doi.org/10.1016/j.jhazmat.2009.12.035.

de los Santos-Villalobos, S. (2018). Colección de microorganismos edáficos y endófitos nativos para contribuir a la seguridad alimentaria nacional Introducción, 191-202.

de los Santos-Villalobos, S., Barrera-Galicia, G. C., Miranda-Salcedo, M. A., \& Peña-Cabriales, J. J. (2012). Burkholderia cepacia XXVI siderophore with biocontrol capacity against Colletotrichum gloeosporioides. World Journal of Microbiology and Biotechnology. DOI: https://doi.org/10.1007/s11274-012-1071-9.

de los Santos-Villalobos, S., de Folter, S., Délano-Frier, J. P., Gómez-Lim, M. A., Guzmán-Ortiz, D. A., \& Peña-Cabriales, J. J. (2013). Growth Promotion and Flowering Induction in Mango (Mangifera indica L. cv "Ataulfo") Trees by Burkholderia and Rhizobium Inoculation: Morphometric, Biochemical, and Molecular Events. Journal of Plant Growth Regulation, 32(3), 615-627. DOI: https://doi.org/10.1007/s00344-013-9329-5.

de los Santos Villalobos, S., Robles, R., Parra Cota, F., Larsen, J., Lozano, P. and Tiedje, J. (2019). Bacillus cabrialesii sp. nov., an endophytic plant growth promoting bacterium 
isolated from wheat (Triticum turgidum subsp. durum) in the Yaqui Valley, Mexico. International Journal of Systematic and Evolutionary Microbiology.

de Souza, R., Ambrosini, A., \& Passaglia, L. M. P. (2015). Plant growth-promoting bacteria as inoculants in agricultural soils. Genetics and Molecular Biology, 38(4), 401-419. DOI: https://doi.org/10.1590/S1415-475738420150053.

Egamberdiyeva, D., \& Höflich, G. (2004). Effect of plant growth-promoting bacteria on growth and nutrient uptake of cotton and pea in a semi-arid region of Uzbekistan. Journal of Arid Environments, 56(2), 293-301. DOI: https://doi.org/10.1016/S0140-1963(03)00050-8.

Eiteman, M.A. et al. (2008) A co-fermentation strategy to consume sugar mixtures effectively. $J$. Biol. Eng. 2, 3.

Ghosh, D., Gupta, A., \& Mohapatra, S. (2019). Dynamics of endogenous hormone regulation in plants by phytohormone secreting rhizobacteria under water-stress. Symbiosis. DOI: https://doi.org/10.1007/s13199-018-00589-w.

Glickmann, E., \& Dessaux, Y. (1995). A Critical Examination of the Specificity of the Salkowski Reagent for Indolic Compounds Produced by Phytopathogenic Bacteria. Applied And Environmental Microbiology (Vol. 61). Retrieved from https://www.ncbi.nlm.nih.gov/pmc/articles/PMC1388360/pdf/hw0793.pdf

Godfray H.C.J., Beddington, J. R., Crute, I. R., Haddad, L., Lawrence, D., Muir, J. F., Pretty, J., Robinson, S., Thomas, S. M. \& Toulmin, C. (2010). The Challenge of Food Security. Science, 5967(January), 812-818. DOI: https://doi.org/10.1126/science.1185383.

Govindasamy, V., Senthilkumar, M., Mageshwaran, V., \& Annapurna, K. (2009). Detection and Characterization of ACC Deaminase in Plant Growth Promoting Rhizobacteria. Journal of Plant Biochemistry and Biotechnology, 18(1), 71-76. DOI: https://doi.org/10.1007/BF03263298.

Grahmann, K., Dittert, K., Verhulst, N., Govaerts, B., \& Buerkert, A. (2019). 15 N Fertilizer recovery in different tillage-straw systems on a Vertisol in north-west Mexico. Soil Use and Management, sum.12495. DOI: https://doi.org/10.1111/sum.12495.

Gray, E. J., \& Smith, D. L. (2005). Intracellular and extracellular PGPR: Commonalities and distinctions in the plant-bacterium signaling processes. Soil Biology and Biochemistry, 37(3), 395-412. DOI: https://doi.org/10.1016/j.soilbio.2004.08.030.

Grobelak, A., Napora, A., \& Kacprzak, M. (2015). Using plant growth-promoting rhizobacteria 
Promoción de crecimiento en trigo (Triticum turgidum L. subsp. durum) por la co-inoculación de cepas nativas de Bacillus aisladas del Valle del Yaqui, México

(PGPR) to improve plant growth. Ecological Engineering, 84, 22-28. DOI: https://doi.org/10.1016/j.ecoleng.2015.07.019.

Guzmán, A., Obando, M., Rivera, D., \& Bonilla, R. (2012). Selección y caracterización de rizobacterias promotoras de crecimiento vegetal (RPCV) asociadas al cultivo de algodón (Gossypium hirsutum). (Spanish). Rev. Colomb. Biotecnol., 14(1), 182-190. Retrieved from

http://search.ebscohost.com/login.aspx?direct=true\&db=fua\&AN=85945255\&lang=es\&si te $=$ ehost-live

He, Y., Wu, Z., Tu, L., \& Shan, C. (2017). Effect of encapsulated Pseudomonas putida Rs-198 strain on alleviating salt stress of cotton. Journal of Plant Nutrition, 40(8), 1180-1189. DOI: https://doi.org/10.1080/01904167.2016.1264595.

Heyrman, J., De Vos, P., \& Logan, N. (2011). Genus XIX. Virgibacillus. (W. B. W. Paul Vos, George Garrity, Dorothy Jones, Noel R. Krieg, Wolfgang Ludwig, Fred A. Rainey, KarlHeinz Schleifer, Ed.), Bergey's Manual of Systematic Bacteriology: Volume 3: The Firmicutes (2nd ed., Vol. 5). Springer Science \& Business Media. Retrieved from http://moscow.sci-hub.bz/2f9a77368ec03cf6b24aeba25c820745/10.1007\%40978-0-38768489-5.pdf

Idriss, E. E., Makarewicz, O., Farouk, A., Rosner, K., Greiner, R., Bochow, H., Richter, T., Borriss, R. (2002). Extracellular phytase activity of Bacillus amyloliquefaciens FZB45 contributes to its plant-growth-promoting effect. Microbiology. DOI: https://doi.org/10.1099/00221287-148-7-2097.

Jorquera, M. A., Hernández, M. T., Rengel, Z., Marschner, P., \& De La Luz Mora, M. (2008). Isolation of culturable phosphobacteria with both phytate-mineralization and phosphatesolubilization activity from the rhizosphere of plants grown in a volcanic soil. Biology and Fertility of Soils. DOI: https://doi.org/10.1007/s00374-008-0288-0.

Joseph, B., Patra, R. R., \& Lawrence, R. (2007). Characterization of plant growth promoting rhizobacteria associated with chickpea (Cicer arietinum L.). International Journal of Plant Production.

Keller, L. and Surette, M.G. (2006) Communication in bacteria: an ecological and evolutionary perspective. Nat. Rev. Microbiol. 4, 249-258.

Khalid, A., Arshad, M., Zahir, Z. A., \& Zahir, Z. A. (2004). Screening plant growth-promoting 
rhizobacteria for improving growth and yield of wheat. The Society for Applied Microbiology Journal of Applied Microbiology, 96, 473-480. DOI: https://doi.org/10.1046/j.1365-2672.2003.02161.x

Kimura, M. (1980). A simple method for estimating evolutionary rates of base substittutions through comparative studies of nucleotide sequences. J. Mol. Evol, 16(1330), 111-120. DOI: https://doi.org/10.1007/BF01731581.

Kloepper, J. W., Reddy, M. S., Rodriguez-Kabana, R., Kenney, D. S., Kokalis-Burelle, N., Martinez-Ochoa, N., \& Vavrina, C. S. (2004). Application for rhizobacteria in transplant production and yield enhancement. In Acta Horticulturae. DOI: https://doi.org/10.17660/ActaHortic.2004.631.28.

Kumar, V., Singh, P., Jorquera, M. A., Sangwan, P., Kumar, P., Verma, A. K., \& Agrawal, S. (2013). Isolation of phytase-producing bacteria from Himalayan soils and their effect on growth and phosphorus uptake of Indian mustard (Brassica juncea). World Journal of Microbiology and Biotechnology. DOI: https://doi.org/10.1007/s11274-013-1299-z

LaPara, T.M., Zakharova, T., Nakatsu, C. H. \& Konopka, A. (2002) Functional and structural adaptations of bacterial communities growing on particulate substrates under stringent nutrient limitation. Microb. Ecol. 44, 317-326.

Lynd, L.R., Weimer, P.J., van Zyl, W.H. \& Pretorius, I.S. (2002) Microbial cellulose utilization: fundamentals and biotechnology. Microbiol. Mol. Biol. Rev. 66, 506-577.

Majeed, A., Abbasi, M. K., Hameed, S., Imran, A., \& Rahim, N. (2015). Isolation and characterization of plant growth-promoting rhizobacteria from wheat rhizosphere and their effect on plant growth promotion. Frontiers in microbiology, 6, 198. https://doi.org/10.3389/fmicb.2015.00198.

Malboobi, M. A., Behbahani, M., Madani, H., Owlia, P., Deljou, A., Yakhchali, B., Moradi, M. \& Hassanabadi, H. (2009). Performance evaluation of potent phosphate solubilizing bacteria in potato rhizosphere. World Journal of Microbiology and Biotechnology. DOI: https://doi.org/10.1007/s11274-009-0038-y

Marra, L. M., Oliveira, S. M. de, Soares, C. R. F. S., \& Moreira, F. M. de S. (2013). Solubilisation of inorganic phosphates by inoculant strains from tropical legumes. Scientia Agricola. DOI: https://doi.org/10.1590/s0103-90162011000500015.

Martínez-Viveros, O., Jorquera, M. ., Crowley, D. ., Gajardo, G., \& Mora, M. . (2010). 
Promoción de crecimiento en trigo (Triticum turgidum L. subsp. durum) por la co-inoculación de cepas nativas de Bacillus aisladas del Valle del Yaqui, México

Mechanisms and practical considerations involved in plant growth promotion by rhizobacteria. Journal of Soil Science and Plant Nutrition. DOI: https://doi.org/10.4067/S0718-95162010000100006.

Matson, P., \& Jewett, P. (2013). Ecosystems and land-use change in the Yaqui Valley: Does agricultural intensification spare land for nature? In Seeds of Sustainability: Lessons from the Birthplace of the Green Revolution. DOI: https://doi.org/10.5822/978-1-61091-177$1 \_4$

Numan, M., Bashir, S., Khan, Y., Mumtaz, R., Shinwari, Z. K., Khan, A. L., ... AL-Harrasi, A. (2018). Plant growth promoting bacteria as an alternative strategy for salt tolerance in plants: A review. Microbiological Research. DOI: https://doi.org/10.1016/j.micres.2018.02.003.

Nyambura Ngamau, C. (2012). Isolation and identification of endophytic bacteria of bananas (Musa spp.) in Kenya and their potential as biofertilizers for sustainable banana production. African Journal of Microbiology Research. DOI: https://doi.org/10.5897/AJMR12.1170.

Onyia, C. E., \& Anyanwu, C. U. (2013). Journal of Yeast and Fungal Research Comparative study on solubilization of tri-calcium phosphate (TCP) by phosphate solubilizing fungi (PSF) isolated from Nsukka pepper plant rhizosphere and root free soil, 4(5), 52-57. DOI: https://doi.org/10.5897/JYFR2013.0120.

Paredes, M. M., \& Espinosa, V. D. (2010). Ácidos Orgánicos Producidos por Rizobacterias que Solubilizan Fosfato: Una Revisión Crítica. Terra Latinoamericana.

Patel, P. R., Shaikh, · S S, \& Sayyed, · R Z. (2018). Modified chrome azurol S method for detection and estimation of siderophores having affinity for metal ions other than iron. Environmental Sustainability, 1, 81-87. DOI: https://doi.org/10.1007/s42398-018-0005-3

Pikovskaya, R. I. (1948). Mobilization of phosphorus in soil in connection with the vital activity of some microbial species. Microbiologia. DOI: https://doi.org/10.1016/S00283932(98)00075-X.

Poudel, R., \& Bhatta, M. (2017). Review of Nutraceuticals and Functional Properties of Whole Wheat. Journal of Nutrition \& Food Sciences, 07(01), 1-6. DOI: https://doi.org/10.4172/2155-9600.1000571.

Richardson, A. E., \& Simpson, R. J. (2011). Soil Microorganisms Mediating Phosphorus 
Availability Update on Microbial Phosphorus. PLANT PHYSIOLOGY. DOI: https://doi.org/10.1104/pp.111.175448.

Robertson, G. P., \& Groffman, P. M. (2015). Chapter 14: Nitrogen Transformations. Soil Microbiology, Ecology and Biochemistry. DOI: https://doi.org/10.1016/B978-0-12415955-6.00014-1.

Robles-Montoya, R. I., Parra Cota, F. I., \& de los Santos Villalobos, S. (2019). Draft genome sequence of Bacillus megaterium TRQ8, a plant growth-promoting bacterium isolated from wheat (Triticum turgidum subsp. durum) rhizosphere in the Yaqui Valley, Mexico. 3 Biotech, 9(5). DOI: https://doi.org/10.1007/s13205-019-1726-4.

Sanches-Santos, M., Hungria, M., \& Nogueira, M. A. (2017). Production of polyhydroxybutyrate (PHB) and biofilm by Azospirillum brasilense aiming at the development of liquid inoculants with high performance. African Journal of Biotechnology, 16(37), 1855-1862. DOI: https://doi.org/10.5897/ajb2017.16162.

Scagliola, M., Pii, Y., Mimmo, T., Cesco, S., Ricciuti, P., \& Crecchio, C. (2016). Characterization of plant growth promoting traits of bacterial isolates from the rhizosphere of barley (Hordeum vulgare L.) and tomato (Solanum lycopersicon L.) grown under Fe sufficiency and deficiency. Plant Physiology and Biochemistry. DOI: https://doi.org/10.1016/j.plaphy.2016.06.002.

Sgroy, V., Cassán, F., Masciarelli, O., Del Papa, M. F., Lagares, A., \& Luna, V. (2009). Isolation and characterization of endophytic plant growth-promoting (PGPB) or stress homeostasisregulating (PSHB) bacteria associated to the halophyte Prosopis strombulifera. Applied Microbiology and Biotechnology. DOI: https://doi.org/10.1007/s00253-009-2116-3

Sheirdil, R. A., Hayat, R., Zhang, X.-X., Abbasi, N. A., Ali, S., Ahmed, M., Khan Khatak, J. Z. \& Ahmad, S. (2019). Exploring Potential Soil Bacteria for Sustainable Wheat (Triticum aestivum L.) Production. Sustainability, 11(12), 3361. DOI: https://doi.org/10.3390/su11123361.

Singh, P., Kumar, V., \& Agrawal, S. (2014). Evaluation of phytase producing bacteria for their plant growth promoting activities. International Journal of Microbiology. DOI: https://doi.org/10.1155/2014/426483

Somasegaran, P., and Hoben, H. J. (1994). Handbook for Rhizobia. Methods in Legume-Rhizobium Technology. Heidelberg, NY: Springer. DOI: 10.1007/978-1- 
Promoción de crecimiento en trigo (Triticum turgidum L. subsp. durum) por la co-inoculación de cepas nativas de Bacillus aisladas del Valle del Yaqui, México

$4613-8375-8$

Sood, G., Kaushal, R., Panwar, G., \& Dhiman, M. (2018). Effect of indigenous plant growthpromoting rhizobacteria on wheat (Triticum aestivum L.) productivity and soil nutrients. Communications in Soil Science and Plant Analysis, 00(00), 1-12. DOI: https://doi.org/10.1080/00103624.2018.1556282.

Thilagar, G., Bagyaraj, D. J., Podile, A. R., \& Vaikuntapu, P. R. (2018). Bacillus sonorensis, a Novel Plant Growth Promoting Rhizobacterium in Improving Growth, Nutrition and Yield of Chilly (Capsicum annuum L.). Proceedings of the National Academy of Sciences India Section $B$ - Biological Sciences, 88(2), 813-818. DOI: https://doi.org/10.1007/s40011-016-0822-z.

United Nations. (2015). World Population Prospects: The 2015 Revision, Key Findings and Advance Tables. (W. P. N. ESA/P/WP.241, Ed.). New York: United Nations.

Valenzuela-Aragón, B., Parra-Cota, F. I., Santoyo, G., Arellano-Wattenbarger, G. L., \& de los Santos-Villalobos, S. (2018). Plant-assisted selection: a promising alternative for in vivo identification of wheat (Triticum turgidum L. subsp. durum) growth promoting bacteria. Plant and Soil, (December). DOI: https://doi.org/10.1007/s11104-018-03901-1.

Valenzuela-Ruiz, V., Robles-Montoya, R. I., Parra-Cota, F. I., Santoyo, G., del Carmen OrozcoMosqueda, M., Rodríguez-Ramírez, R., de los Santos-Villalobos, S. (2019). Draft genome sequence of Bacillus paralicheniformis TRQ65, a biological control agent and plant growth-promoting bacterium isolated from wheat (Triticum turgidum subsp. durum) rhizosphere in the Yaqui Valley, Mexico. 3 Biotech, 9(11): 436-442. DOI: $10.1007 / \mathrm{s} 13205-019-1972-5$

Villa-Rodríguez, E., Lugo-Enríquez, C., de los Santos-Villalobos, S., Parra-Cota, F. I., \& Figueroa-López, P. (2016). First Report of Cochliobolus sativus Causing Spot Blotch on Durum Wheat (Triticum durum) in The Yaqui Valley, Mexico . Plant Disease, 100(11), 2329. DOI: https://doi.org/10.1094/pdis-05-16-0634-pdn

Villa-Rodriguez, Eber, Parra-Cota, F., Castro-Longoria, E., Lopez-Cervantes, J., \& de los SantosVillalobos, S. (2019). Bacillus subtilis TE3: a promising biological control agent against Bipolaris sorokiniana, the causal agent of spot blotch in wheat (Triticum turgidum L. subsp. durum). Biological Control, 132(In press), 135-143. DOI: https://doi.org/10.1016/j.biocontrol.2019.02.012. 
Villarreal-Delgado, M. F., Villa-Rodríguez, E. D., Cira-Chávez, L. A., Estrada-Alvarado, M. I., Parra-Cota, F. I., \& De los Santos-Villalobos, S. (2018). El género Bacillus como agente de control biológico y sus implicaciones en la bioseguridad agrícola. Revista Mexicana de Fitopatología, Mexican Journal of Phytopathology, 36(1), 95-130. DOI: https://doi.org/10.18781/R.MEX.FIT.1706-5.

Vincent, J. M., and Humphrey, B. (1970). Taxonomically significant group antigens in Rhizobium. J. Gen. Microbiol. 63, 379-382. DOI: 10.1099/00221287-63-3-379.

Wahyudi, A. T., Astuti, R. P., Widyawati, A., Meryandini, A., \& Nawangsih, A. A. (2011). Characterization of Bacillus sp. strains isolated from rhizosphere of soybean plants for their use as potential plant growth for promoting Rhizobacteria. Journal of Microbiology and Antimicrobials.

Walia, A., Mehta, P., Chauhan, A., \& Shirkot, C. K. (2014). Effect of Bacillus subtilis strain CKT1 as inoculum on growth of tomato seedlings under net house conditions. Proceedings of the National Academy of Sciences India Section B - Biological Sciences, 84(1), 145-155. DOI: https://doi.org/10.1007/s40011-013-0189-3.

Won, S.-J., Kwon, J.-H., Kim, D.-H., \& Ahn, Y.-S. (2019). The Effect of Bacillus licheniformis MH48 on Control of Foliar Fungal Diseases and Growth Promotion of Camellia oleifera Seedlings in the Coastal Reclaimed Land of Korea. Pathogens. DOI: https://doi.org/10.3390/pathogens8010006. 